\title{
T-Box20 Suppresses Oxidized Low-Density Lipoprotein-induced Human Vascular Endothelial Cell Injury by Upregulation of PPAR- $\gamma$
}

\author{
Tao Shen ${ }^{\mathrm{a}, \mathrm{e}}$ Yuping Zhu ${ }^{\mathrm{a}, \mathrm{b}, \mathrm{e}}$ Jigar Patel ${ }^{\mathrm{c}, \mathrm{e}}$ Yang Ruan ${ }^{\mathrm{d}}$ Beidong Chen ${ }^{\mathrm{a}}$ Gexin Zhao \\ Yuan Cao Jing Pang ${ }^{a}$ Hangbang Guo Hongxia Li $^{a}$ Yong Man ${ }^{a}$ Shu Wang ${ }^{a}$ \\ Jian Lia
}

\begin{abstract}
aKey Laboratory of Geriatrics, BeijingHospital and Beijing Institute of Geriatrics, Ministry of Health, 'Department of Ultrasound, Capital Medical University Affiliated Beijing Anzhen Hospital, Beijing Institute of Heart, Lung and Blood Vessel Diseases, Beijing, China; 'Veterans Affairs Medical Center and University of California, San Diego, California, USA; 'Department of Emergency, Capital Medical

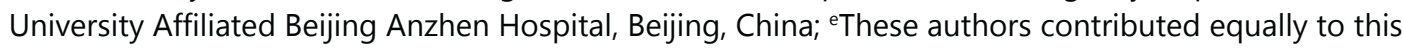
work
\end{abstract}

\section{Key Words}

T-box $20 \cdot$ Oxidized low-density lipoprotein $\bullet$ Oxidative stress $\bullet$ Endothelial cell $\bullet$ Atherosclerosis

\begin{abstract}
Background: Atherosclerosis is a chronic inflammation disease which is initiated by endothelial cell injury. Oxidized low-density lipoprotein (ox-LDL) is directly associated with chronic vascular inflammation. Many transcription factors take part in the initiation and progression of atherosclerosis. As a transcription factor mainly expressed in cardiovascular system, T-box20 (Tbx20) plays an important role in embryonic cardiovascular system development and homeostasis. However, the role of Tbx20 in endothelial cell injury and atherosclerosis is still not clear. We showed that Tbx20 might affect ox-LDL-induced inflammatory responses in human umbilical vein endothelial cells (HUVECs). Methods and Results: First, Tbx20 expression was down regulated in the C57BL/6 mice with high-fat diet-induced artery injury, which was accompanied by elevated reactive oxygen species (ROS) generation and cell adhesion molecule expression. Second, ox-LDL led to concurrent decreased Tbx20 expression and increased levels of ROS and adhesion molecules in the HUVECs. Third, over-expression of Tbx20 by adenovirus reduced ox-LDL-induced HUVEC injury via attenuation of ROS generation and cell adhesion molecule expression. Fourth, knock down of Tbx20 by siRNA significantly increased adhesion molecule expression and decreased cell viability. Moreover, Tbx20 could directly regulate PPAR $-\gamma$ expression, as shown by Tbx20 knock down and PPAR- $\gamma$ inhibition, which significantly reversed Tbx20's HUVEC protection effect. Conclusions: These results indicate that misregulation of Tbx20 could reduce HUVEC tolerance of ox-LDL-induced cell injury, suggesting that Tbx20 might be a crucial regulator and potential therapeutic target for atherosclerosis.
\end{abstract}




\section{Cellular Physiology and Biochemistry}

Cell Physiol Biochem 2013;32:1137-1150

\begin{tabular}{l|l}
\hline DOI: $10.1159 / 000354514$ & (C) 2013 S. Karger AG, Basel
\end{tabular}

www.karger.com/cpb

Shen/Zhu/Patel et al.: T-Box20 Protects Vascular Endothelial Cells

\section{Introduction}

Atherosclerosis is a slowly progressing inflammatory disease of the medium- and large-sized arteries, involving interactions between endothelial cells, vascular smooth muscle cells, macrophages, platelets, and cytokines [1]. Oxidized low-density lipoprotein (ox-LDL) has been demonstrated to induce multiple functional alterations and is involved in the pathogenesis of atherosclerosis [2]. During the development of atherosclerosis, oxLDL stimulates transformation of macrophages and vascular smooth muscle cells into lipid-rich foam cells, induces proliferation and migration of vascular cells, and attenuates endothelial regeneration. At the molecular level, ox-LDL is shown to promote expression of adhesion molecules, heat shock proteins, and coagulation proteins; to suppress production of endothelium-derived relaxing factor (nitric oxide) and prostacyclin; and to induce expression of various proinflammatory cytokines and growth factors in the vascular cells [3-7].

It is thought that endothelial dysfunction and inflammation are the precursors of atherosclerosis $[8,9]$. Normally, endothelium can prevent interaction of vascular muscle layers with circulating monocytes and lymphocytes. However, many atherogenic stresses or risk factors (e.g., dyslipidemia, hypertension, hyperglycemia, smoking, aging, etc) induce excessive generation of reactive oxygen species (ROS), which may injure endothelial cells and induce inflammatory responses $[10,11]$. The damaged or dysfunctional endothelial cells then synthesize and release pro-inflammatory factors, especially intercellular adhesion molecule-1(ICAM-1) and vascular cell adhesion molecule-1(VCAM-1), leading to attachment of the inflammatory cells to the dysfunctional endothelial cells $[12,13]$. It is likely that these pro-inflammatory factors play a major role in the formation of atherosclerotic plaques. Therefore, controlling inflammatory response is an important therapeutic strategy for prevention of atherosclerosis.

Coordinated expression of transcription factors in the cardiovascular system regulates gene expression programs responsible for cardiovascular function. T-box (Tbx) transcription factors are highly conserved across species, expressed in a wide variety of tissue types, and are required for the development of diverse organs and tissues [14]. T-box genes regulate patterning and cell fate, cell survival and/or proliferation, and are also of great clinical relevance. Mutations in T-box genes were linked to many human disorders. Tbx20 is a T-box transcription factor expressed in the cardiovascular and nervous systems [14-16]. Previous studies indicated that Tbx20 plays a critical role in heart development, driving cardiac proliferation and a chamber-specific program of gene expression. Absence of Tbx20 leads to a severely hypoplastic cardiovascular system and embryonic lethality at midgestation $[16,17]$. Accordingly, in humans, mutations in Tbx20 are associated with various forms of congenital cardiovascular disease and dilated cardiomyopathy $[18,19]$. However, no report has described clear the links between Tbx20, adult aging, and atherosclerosis.

Previous bioinformatics and ChIP-seq study found that peroxisome proliferatoractivated receptor gamma (PPAR- $\gamma$ ) perhaps is a direct downstream target of Tbx20 [20]. In recent years, PPAR- $\gamma$ was reported to be a target for the treatment of type 2 diabetes mellitus. Furthermore, it was received attention for its potential pathologic link and therapeutic potential in many other human diseases, including atherosclerosis, obesity, and cancer. PPAR- $\gamma$ agonists have been clinically used in the treatment of dyslipidemia and hyperglycemia. PPAR- $\gamma$ decreases the inflammatory response in many cardiovascular cells, particularly endothelial cells [21-23]. Recently, the PPAR- $\gamma$ agonist pioglitazone was shown to be effective in reducing inflammation in atherosclerosis disease models. For example, in these models, the levels of matrix metalloproteinase (MMP), TNF $\alpha$ and other cytokines were found to be reduced [23-26].

In our current investigation, our goal was to explore the molecular mechanisms by which Tbx20 is involved in the regulation of oxidative stress and endothelial cell injury in mouse and human endothelial cell atherosclerosis models. Our hypothesis was that Tbx20 


\section{Cellular Physiology and Biochemistry}

Cell Physiol Biochem 2013;32:1137-1150

\begin{tabular}{l|l}
\hline DOI: $10.1159 / 000354514$ & (c) 2013 S. Karger AG, Basel
\end{tabular}

www.karger.com/cpb

Shen/Zhu/Patel et al.: T-Box20 Protects Vascular Endothelial Cells

can be linked to endothelial cell survival and function, and the misregulation of Tbx20 is directly connected to the development of atherosclerosis.

\section{Materials and Methods}

\section{Reagents}

Anti-ICAM-1, VCAM-1, Tbx20, Caspase-3 and Bax antibodies were purchased from Santa Cruz Biotechnologies (CA, USA). Anti-PPAR- $\gamma$ was purchased from Cell signal technology (CA, USA). PPAR- $\gamma$ selective antagonist T0070907 was purchased from Sigma-Aldrich (MO, USA). Human monocyte cell line U-937 was obtained from cell bank of the Chinese Academy of Medical Science and Peking Medical Collage. Unless otherwise indicated, all chemicals were purchased from Sigma or Amersco.

\section{Cell culture}

Human umbilical vein endothelial cells (HUVECs) were isolated from freshly derived umbilical cords by digestion with collagenase as described by Jaffe et al [24, 25, 27]. Umbilical cords were donated anonymously after informed consent according to national ethical legislation. Cells were routinely grown in M199 medium, supplemented with 20\% heat-inactivated fetal bovine serum (FBS), 2 mM glutamine, and antibiotics $(10 \mu \mathrm{M}$ penicillin $\mathrm{G}$ and $10 \mu \mathrm{M}$ Streptomycin). HUVECs at passages 3-5 were used in the current study. The study protocol was approved by the ethics committee of Beijing Institute of Geriatrics, Ministry of Health (No. 2006-05) and conforms to the principles outlined in the Declaration of Helsinki for use of human tissue or subjects. Written informed consent was obtained from all donors in this study.

\section{Animals}

Male C57BL/6 mice were provided by Peking University Health Science Center (purchased from Jackson Laboratory). 8 Week-old C57BL/6 mice were fed normal diet as control or Western-type High-Fat Diet (HFD) containing $21 \%$ fat, $19.5 \%$ casein, and $0.21 \%$ cholesterol for 6 weeks to early artery injury. Animals were kept at a temperature of $20-24^{\circ} \mathrm{C}$ and a humidity (45-55\%)-controlled environment with a $12-12 \mathrm{~h}$ light-dark cycle. The mice were anesthetized by isoflurane and euthanized by cervical dislocation, and the arteries were dissected for further analysis. All animal experiments conformed to protocols approved by the Beijing Hospital, Ministry of Health Animal Use and Care Committee and to the Guide for Care and Use of Laboratory Animals (NIH Publication \#85-23, revised 1996).

\section{Construction of adenovirus}

Recombinant adenoviruses containing the mouse Tbx20 cDNA (Ad-Tbx20) were prepared by the AdEasy system using the manufacturer's protocol. The GFP adenovirus (Ad-GFP) was used as the control in this study. Adenovirus mediated gene transfer was implemented for $24 \mathrm{~h}$ following $16 \mathrm{~h}$ quiescent in M199 with $2 \%$ FBS. Ad-Tbx20 infection was performed at a multiplicity of infection (m.o.i.) of 50. An Ad-GFP was added in the control groups to keep the amount of virus consistent.

Preparation of $L D L$ and $o x-L D L$

Human LDL was isolated from fresh serum by sequential ultracentrifugation. LDL was oxidized with $\mathrm{CuSO}_{4}(5 \mu \mathrm{M})$ for $16 \mathrm{~h}$ at $37^{\circ} \mathrm{C}$, and then the oxidation was stopped by addition of EDTA $(20 \mu \mathrm{M})$. The oxidation was confirmed by the thiobarbituric acid-reactive substance assay. The ox-LDL preparation was filtered through $0.22-\mu \mathrm{m}$ filters and stored at $4^{\circ} \mathrm{C}$. Protein concentration of ox-LDL was determined by spectrophotometer at the wavelength of $280 \mathrm{~nm}$ (UV-visible spectrophotometer; Shimadzu, Kyoto) [28].

\section{Ox-LDL treatment}

After being stimulated for various times with $0.1 \mathrm{mg} / \mathrm{ml}$ ox-LDL in 2\% FBS M199 medium [28], the cells were lysed by dissolving them in the lysis buffer (Santa Cruz, CA, US), and then the samples were sonicated and centrifuged at 12,000g for $20 \mathrm{~min}$. The lysates were subjected to Western blot with specific antibodies. 


\section{Cellular Physiology and Biochemistry}

Cell Physiol Biochem 2013;32:1137-1150

\begin{tabular}{l|l}
\hline DOI: $10.1159 / 000354514$ & (C) 2013 S. Karger AG, Basel
\end{tabular}

www.karger.com/cpb

Shen/Zhu/Patel et al.: T-Box20 Protects Vascular Endothelial Cells

Real-time RT-PCR

Real-time RT-PCR was performed using the iCycler IQ system (Bio-Rad) in combination with iQ SYBR Green Real-Time RT-PCR Supermix (Bio-Rad) according to the manufacturer's protocol. Briefly, total RNA was extracted using TriReagent (Sigma-Aldrich). $1 \mu \mathrm{g}$ of RNA was then reverse transcribed to first-strand cDNA using random primers and Moloney murine leukemia virus reverse transcriptase (Promega) following the manufacturer's protocol. The PCR profile was as follows: $95^{\circ} \mathrm{C}$ for $30 \mathrm{~s}, 40$ cycles at $95^{\circ} \mathrm{C}$ for $5 \mathrm{~s}, 60^{\circ} \mathrm{C}$ for $34 \mathrm{~s}$. The amount of SYBR Green was measured at the end of each cycle. The cycle number at which the emission intensity of the sample rose above the baseline is referred to as the threshold cycle and was proportional to the target concentration. The data presented are the average of 3-5 independent experiments.

\section{Western blot analysis}

Cell lysates were analyzed by Western blot as described previously [29]. GAPDH antibody (SigmaAldrich) was used for normalization. ImageJ software (NIH) was used to perform densitometry analysis (http://rsb.info.nih.gov/ij/).

\section{Hoechst 33342 staining}

Nuclear fragmentation was detected by incubating in 10mM Hoechst 33342 in fixed cells $(70 \%$ Methanol and 30\% acetone), as previously described[29]. 500-700 cells in 10 randomly chosen fields from each dish were counted for the percentage of apoptotic nuclei. Each data point shows the results from 5000 7000 cells of 4-8 independent experiment.

\section{MTT cell viability assay}

Cells were infected with Adv-GFP or Adv-Tbx20 at m.o.i. of 50 and cultured for $24 \mathrm{~h}, 0.5 \mathrm{mg} / \mathrm{ml}$ 3-[4,5-dimethylthiazol-2-yl]-2,5-diphenylterazolium bromide was added to cells for $4 \mathrm{~h}$ and the absorbance at $490 \mathrm{~nm}$ was measured, as described previously [29]. The MTT Kit was purchased from Roche Applied Science (Indianapolis, Indiana).

\section{DNA laddering}

Cells were lysed in the lysis buffer (10 mM Tris-Cl pH8.0, $150 \mathrm{mM} \mathrm{NaCl}, 10 \mathrm{mM}$ EDTA, 0.4\% SDS, and $100 \mathrm{~g} / \mathrm{mL}$ protease $\mathrm{K}$ ) and were incubated at $50^{\circ} \mathrm{C}$ for $5 \mathrm{~h}$ with gentle agitation; the DNA was then extracted with phenol/CHCl3/isoamyl alcohol and $\mathrm{CHCl} 3$ /isoamyl alcohol. DNA fragmentation was detected by loading $10 \mu \mathrm{g}$ of total DNA onto a $2 \%$ agarose gel; the gel was run in Tris-acetate-EDTA buffer and was visualized by ethidium bromide staining [29].

\section{In situ detection of ROS}

To evaluate vascular ROS production in situ, the living HUVECs were stained with $10 \mu \mathrm{mol} / \mathrm{L}$ DHE (Sigma) for $30 \mathrm{~min}$ in a dark humidified chamber at $37^{\circ} \mathrm{C}$. The ROS generation was labeled with the red fluorescence, and visualized by a fluorescence microscopy. The relative DHE fluorescent intensity was analyzed by Image J software (NIH) (http://rsb.info.nih.gov/ij/).

\section{Monocyte and HUVEC adhesion assay}

For adhesion studies, HUVECs were cultured in 6-well plates in M199 with 20\% FBS for $48 \mathrm{~h}$ to achieve 90-95\% confluence, transduced with Ad-Tbx20 or Ad-GFP for $24 \mathrm{~h}$, and then stimulated with 100ug/mL ox-LDL for $12 \mathrm{~h}$. Human monocytes, U937 cells, were incubated in the medium1640 with 10\% FBS and $5 \mu \mathrm{M}$ BCECF AM (2',7'-bis-(2-carboxyethyl)-5-(and-6)-carboxyfluorescein, acetoxymethyl ester, Beyotime, Jiangsu, China) at $37^{\circ} \mathrm{C}$ for $1 \mathrm{~h}$ to label the monocytes with fluorescence, and then washed 3 times with fresh medium 1640. After labeling the U937 cells with BCECF AM, ox-LDL treated HUVEC were washed and a suspension of prepared U937 cells $\left(1 \times 10^{6}\right.$ cells $\left./ \mathrm{ml}\right)$ was added for $30 \mathrm{~min}$. Non-adherent U937 cells were removed by washing and adherent cells were counted using an inverted phase contrast fluoresce microscope. The number of attached leukocytes was counted in each of 20 microscopic fields by the Image J software (NIH).

In the experiments of MTT labeled monocytes and HUCEC adhesion assay, U937 cells were incubated with medium 199 with 10\% FBS and 50ug/mL MTT (3-(4,5-Dimethylthiazol-2-yl)-2,5-diphenyltetrazolium bromide) at $37^{\circ} \mathrm{C}$ for $2 \mathrm{~h}$ to label the monocytes, and then washed 3 times with fresh medium 1640 . The 
A.
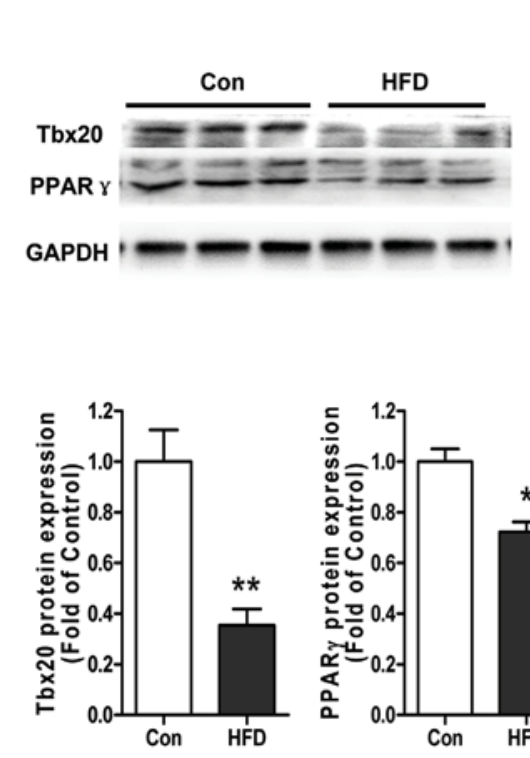

B.

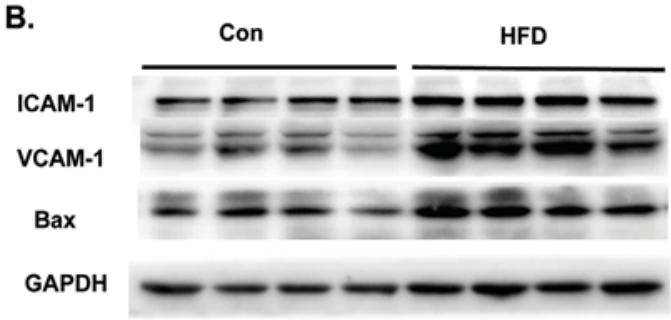

Fig. 1. Decreased Tbx20 expression in the C57/B6 mice fed with high-fat diet. (A): Tbx20 and PPAR- $\gamma$ expression assayed by Western blot and the average data in control and HFD mouse artery samples $(n=6)$. $(B)$ : Western blot analysis and the average data of ICAM-1, VCAM-1 and Bax abundance in high-fat diet mice $(\mathrm{n}=6) .\left({ }^{* *} \mathrm{P}<0.01,{ }^{* * *} \mathrm{P}<0.001\right)$.

treated HUVECs were washed and a suspension of prepared U937 cells $\left(110^{6} \mathrm{cells} / \mathrm{ml}\right)$ was added for 30 min. Non-adherent U937 cells were removed by washing and $400 \mu \mathrm{l}$ DMSO was added to the adherent cells in each well, mixing thoroughly with a pipette and absorbance at $490 \mathrm{~nm}$ was measured.

\section{RNA interference by siRNA}

For the siRNA assay, 21 nucleotide small interference RNA (siRNA) comprising 19 nucleotides and a dTdT overhang at each 3'-terminus corresponding to the 425-443 and 576-596 coding region of rat Tbx20, were chemically synthesized. siRNA1: sense 5'-CUG AGG CCA AGU ACA UAG UTT-3' and antisense 5'-ACU AUG UAC UUG GCC UCA GTT-3'; siRNA2: sense 5'-CGG UGA GCA ACU ACU CAA ATT-3' and antisense 5'-UUU GAG UAG UUG CUC ACC GTT-3'; scramble: 5'-UUC UCC GAA CGU GUC ACG UTT-3' and antisense 5'-ACG UGA CAC GUU CGG AGA ATT-3' by Genepharma Co. China. HUVECs were transduced with Effectene Transduceion Reagent (Qiagen) according to the manufacturer's protocol.

\section{Statistical analyses}

All of the statistical calculations were performed using the GraphPad Prism 5 software program. The data were expressed as the mean \pm SEM. Student's $t$-test was used to compare two conditions, and a one-way ANOVA with Bonferroni correction was used for multiple comparisons. Probability values of less than 0.05 were considered significant.

\section{Results}

Decreased expression of Tbx20 in the C57BL/6 mice fed with high-fat diet and HUVECs treated by ox-LDL in vitro

After a high-fat diet (HFD) for 6 weeks, the body weight of C57BL/6 mice increased $15.5 \%$ compared with the normal diet mice. Artery Tbx2 0 and PPAR- $\gamma$ expression decreased significantly in the HFD group compared with the control group assayed by Western blot (Fig. 1A). However, artery VCAM-1, ICAM-1 and Bax expression elevated markedly in the 
A.

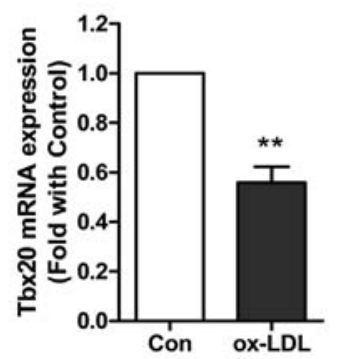

B.
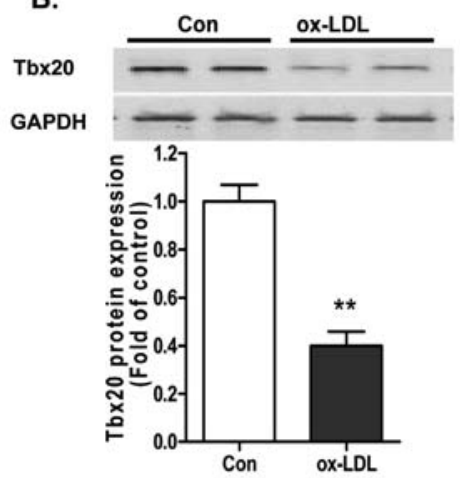

c.

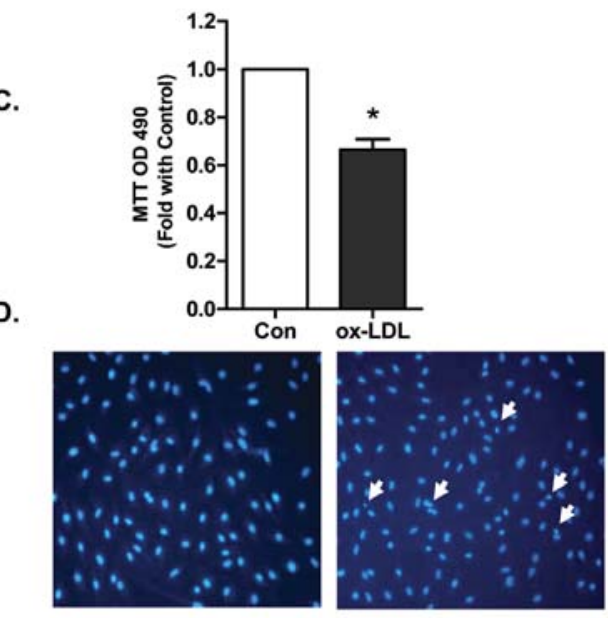

D.

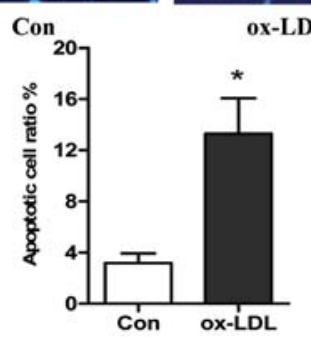

Fig. 2. Decreased Tbx20 expression in ox-LDL treated HUVECs. $A$ - $B$ : Tbx20 mRNA $(A)$ and protein $(B)$ expression in the HUVECs treated by $0.1 \mathrm{mg} / \mathrm{ml}$ of ox-LDL for $8 \mathrm{~h}$ and $24 \mathrm{~h}$. $C$-D: Ox-LDL markedly increased HUVEC death assayed by MTT(C), Hoechst33342 staining photos (white arrow indicates the apoptotic body or apoptotic cell) and the average data $(D)$ in the HUVECs. ( $\mathrm{n}=4,{ }^{*} \mathrm{P}<0.05$, $\left.{ }^{* *} \mathrm{P}<0.01\right)$.

HFD group compared with the control group (Fig. 1B). These results indicate decreased expression of Tbx20 in the high fat diet-induced mouse artery injury.

In the ox-LDL treated HUVEC model, as shown in Figure 2A and 2B, 100ug/mL ox-LDL suppressed Tbx20 mRNA and protein expression in HUVECs, as measured by real-time RTPCR and Western blot. HUVEC viability was profoundly reduced after ox-LDL treatment, as assayed by MTT assay (Fig. 2C) and Hoechst33342 staining (Fig. 2D). Similarly, serum deprivation, hypoxia, or ischemia also attenuated Tbx20 gene expression and endothelial viability (data not shown).

\section{Tbx20 overexpression blocked ox-LDL induced oxidative stress in HUVECS}

The HUVECs transduced with Ad-Tbx20, but not with the Ad-GFP (as a vector control), substantially increased Tbx20 protein abundance (Fig. 3A-B). Figure 3C illustrates the cell morphology of HUVECs in bright field light microscopy and fluorescence microscopy. As shown in Figure 3D-3E: exposure of HUVECs to $100 \mathrm{ug} / \mathrm{mL}$ ox-LDL for $8 \mathrm{~h}$ significantly increased intracellular ROS generation as measured by DHE fluorescence intensity. In contrast, oxLDL-induced ROS generation was significantly decreased in the cells overexpressed with Ad-Tbx20 (50m.o.i.) for $24 \mathrm{~h}$ compared to the HUVECs transduced with Ad-GFP (50m.o.i.).

\section{Tbx20 overexpression attenuated ox-LDL-induced HUVEC injury}

Of note, Tbx20 overexpression could block ox-LDL-induced HUVEC injury, assayed by Hoechst 33342 staining (Fig. 4A, 4B), MTT assay (Fig. 4C) and DNA laddering (Fig. 4D), indicating a potential protective effect. On average, the percentage of injured HUVECs was decreased by $50 \%$ in the cells transduced with Ad-Tbx20 relative to those transduced 


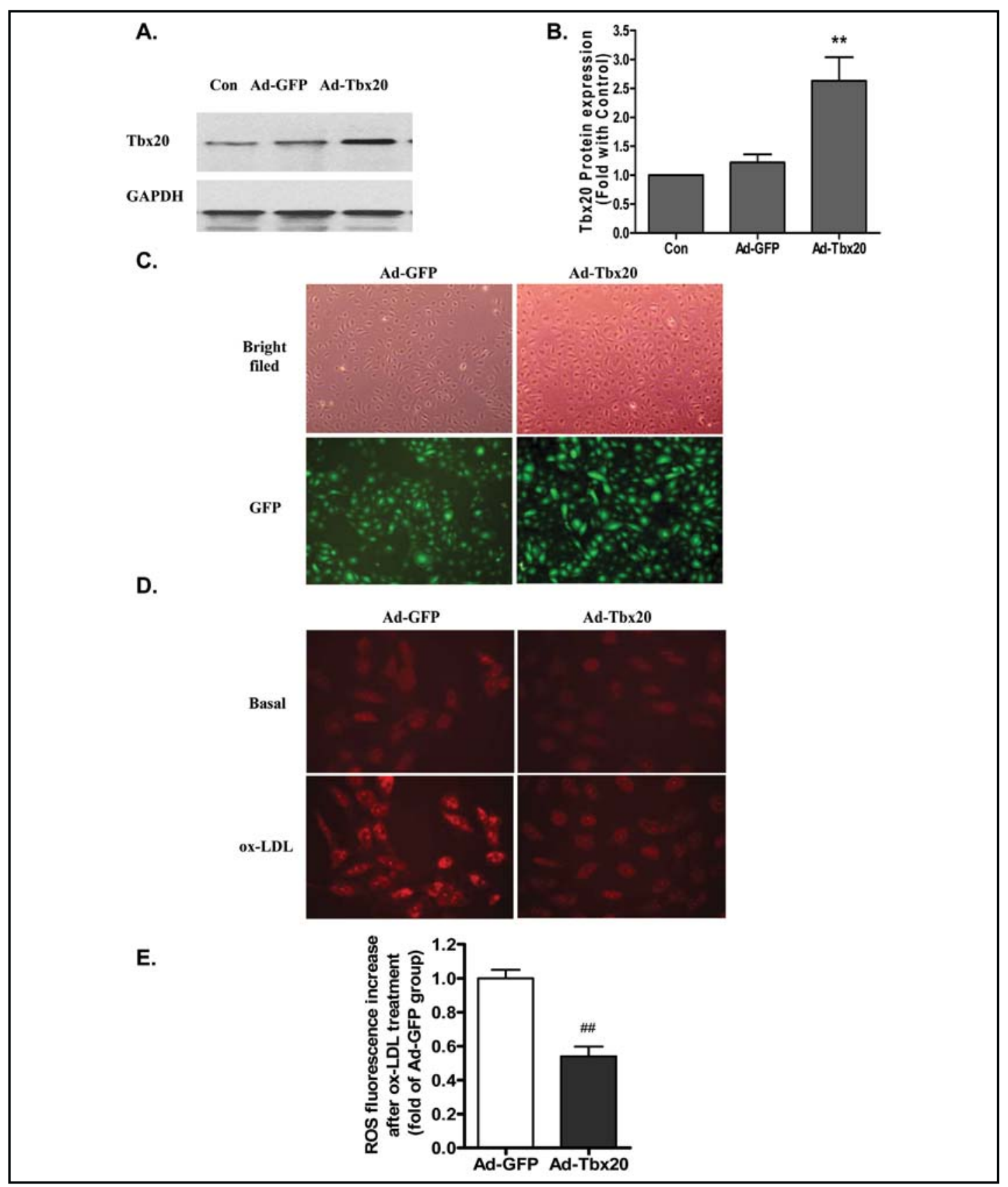

Fig. 3. Tbx20 overexpression attenuates ox-LDL-induced oxidative stress. HUVECs were infected with AdTbx20 or Ad-GFP (both at 50m.o.i. for 24 h). (A): Tbx20 protein expression, assayed by Western blot, in the control, Ad-GFP and Ad-Tbx20 transduced HUVECs (both at 50m.o.i. for 24 h). (B): The average data of Tbx20 protein expression in the control, Ad-GFP and Ad-Tbx20 transduced HUVECs $(C)$ : Representative morphology of HUVECs in the bright field and inverted fluorescence microscope. (D): DHE staining in the HUVECs infected with Ad-GFP or Ad-Tbx20, and with or without $100 \mathrm{ug} / \mathrm{ml}$ ox-LDL treatment. (E): The average data of ROS fluorescence in Ad-GFP and Ad-Tbx20-transduced HUVECs after ox-LDL treatment. (n=3, ** $\mathrm{P}<0.01$ vs control; \#\# $\mathrm{P}<0.01$ vs Ad-GFP+ox-LDL).

with Ad-GFP (both at 50m.o.i. for 24 h). Also, Tbx20 overexpressed HUVECs treated by oxLDL displayed more full length caspase- 3 and less pro-apoptotic proteins such as cleaved caspase-3 and Bax than Ad-GFP control group (Fig. 4E). 


\section{Cellular Physiology $\quad$ Cell Physiol Biochem 2013;32:1137-1150 \\ \begin{tabular}{l|l|l} 
DOI: 10.1159/000354514 & O 2013 S. Karger AG, Basel
\end{tabular} and Biochemistry Publisned onine: November 11, 2013 www.karger.com/cpb

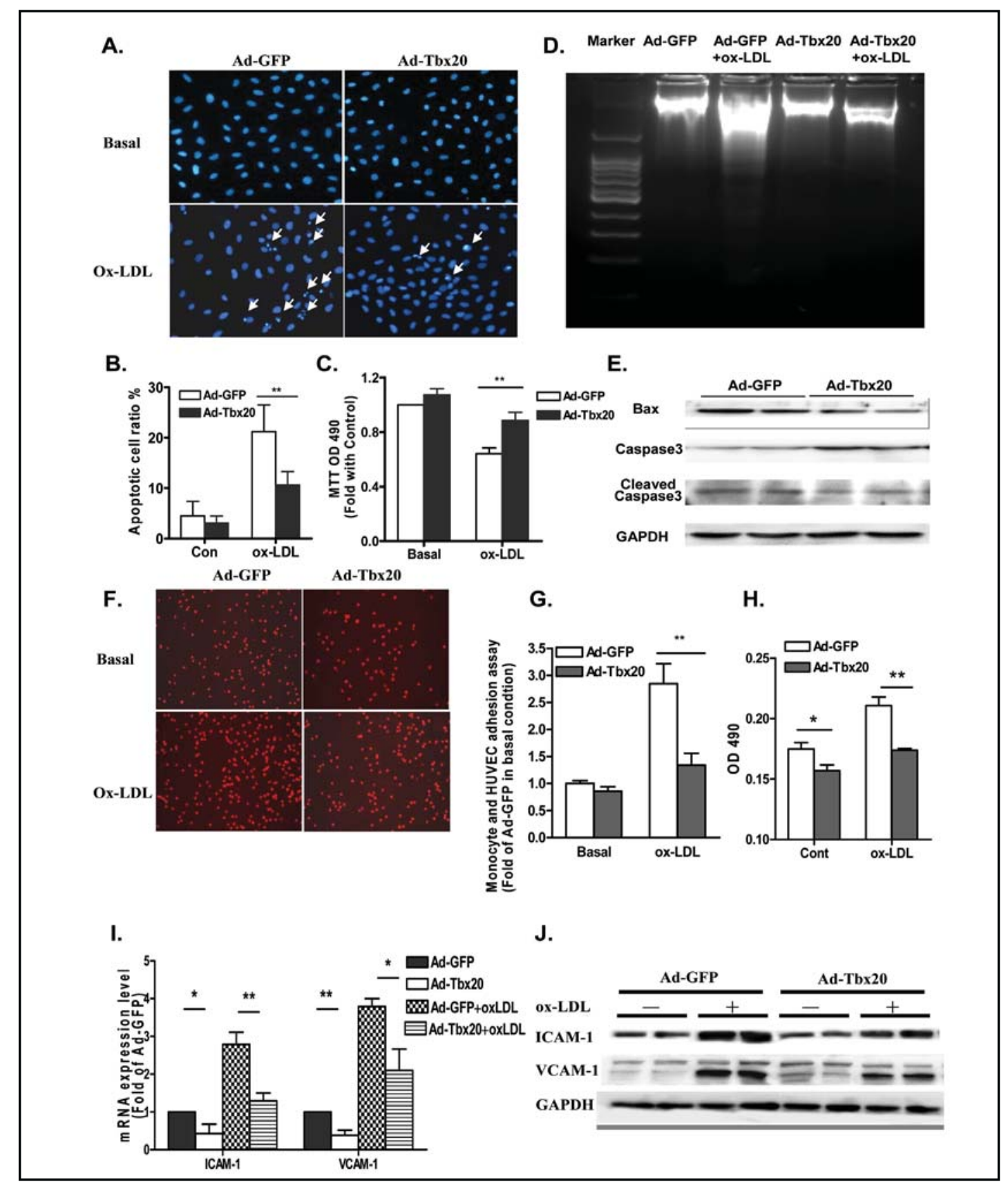

Fig. 4. Tbx20 overexpression attenuates HUVEC injury and monocyte adhesion to HUVECs during ox-LDL stimulation. HUVECs were infected with Ad-Tbx20 or Ad-GFP (both at 50m.o.i. for $24 \mathrm{~h}$ ). (A-C): Tbx20 overexpression markedly reduced HUVEC death, assayed by Hoechst33342 staining (A-B) (n=3, the total number of cells in each group is 800 1000) and MTT assay (C) $(n=3)$. (D): HUVEC apoptosis detected by DNA laddering in Ad-GFP group, ox-LDL-treated Ad-GFP group, Ad-Tbx20 group and ox-LDL-treated Ad-Tbx20 group (n=3). (E): Bax and caspase-3 levels assayed by Western blot in Ad-GFP and Ad-Tbx20 group (n=4). $(F-G)$ : Monocyte and HUVEC adhesion assay by BCECF AM staining $(F)$ and the average data of relative cell number fold change $(G)$ in the HUVECs transduced with Ad-GFP or Ad-Tbx20, and with or without 0.1mg/ $\mathrm{ml}$ of ox-LDL treatment for $12 \mathrm{~h}$. (H): The human U937 cells were preloaded with MTT for $2 \mathrm{~h}$ and incubated with HUVECs for $30 \mathrm{~min}$. The average fold change of the absorbance at $490 \mathrm{~nm}$ indicated the monocyte and HUVEC adhesion rate. (I-J): The expression of cell adhesion molecules such as ICAM- 1 and VCAM-1, assayed by real time RT-PCR and Western blot, in Ad-GFP and Ad-Tbx20-transduced HUVECs (both at 50m.o.i. for $24 \mathrm{~h})$. 


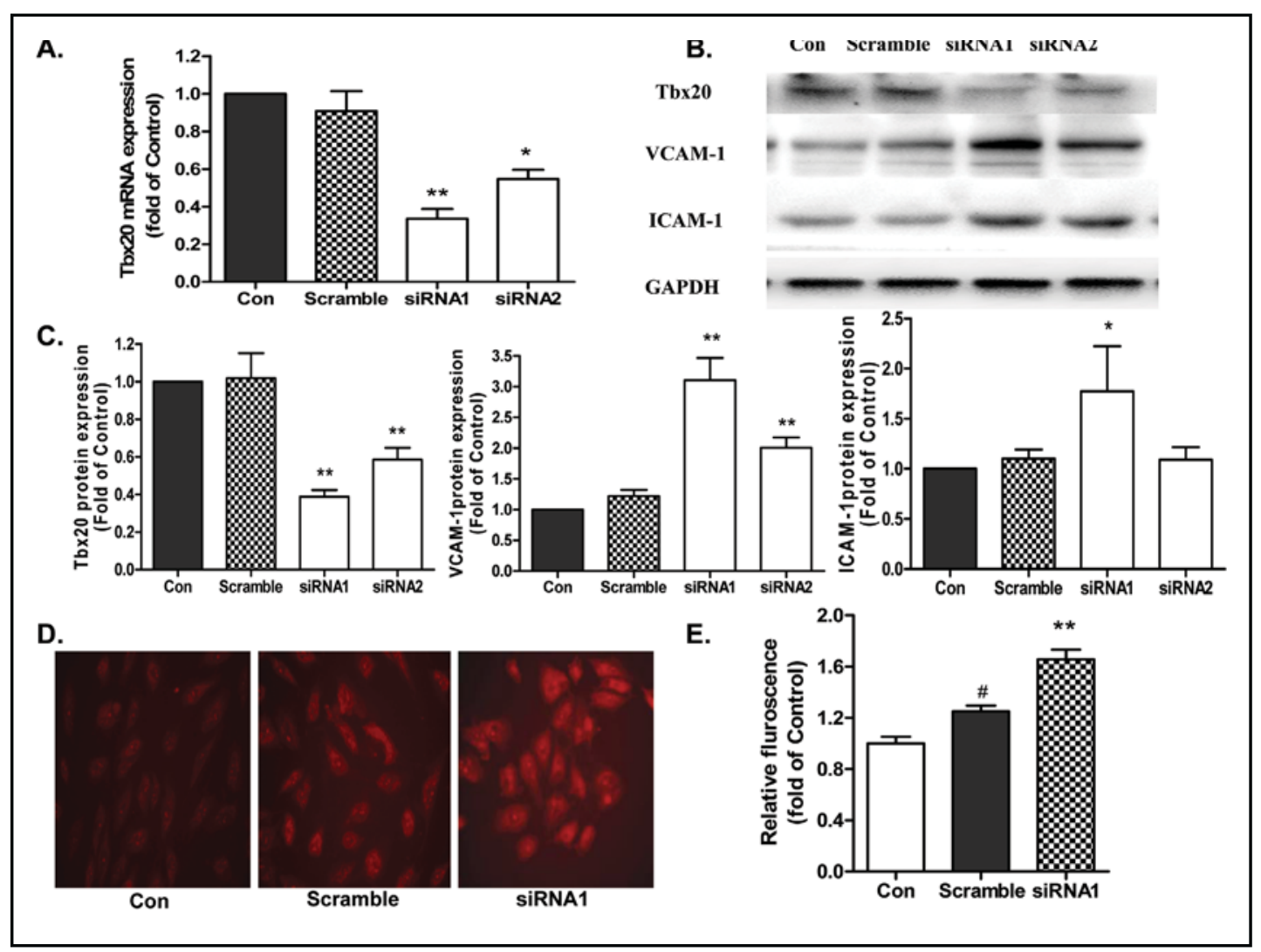

Fig. 5. Tbx20 ablation exaggerates ox-LDL-induced adhesion molecule expression. (A): Tbx20 mRNA expression assayed by real time RT-PCR in the control, scramble and two different Tbx20 siRNA (siRNA1 and siRNA2); $B$-C: Western blot analysis $(B)$ and the average data $(C)$ of Tbx20, VCAM-1 and ICAM-1 abundance in the HUVECs. $\left(\mathrm{n}=3,{ }^{*} \mathrm{P}<0.05,{ }^{* *} \mathrm{P}<0.01\right)$. $D$-E: Tbx20 knock down by siRNA1 could increase the ROS production in the HUVECs assayed by DHE staining $(D)$ and the average data of fluorescence intensity $(E)(\mathrm{n}=6)$.

Tbx20 overexpression inhibited ox-LDL-induced adhesion molecular expression

In our previous work we found that 0.05 to $0.3 \mathrm{mg} / \mathrm{ml}$ of ox-LDL could induce the expression of cell adhesion molecules in a concentration-dependent manner. In order to confirm this finding, $0.1 \mathrm{mg} / \mathrm{ml}$ of ox-LDL was used in the present study. As shown in Figure 4 F-4H, ox-LDL increased U-937 adhesion to HUVECs assayed by $5 \mu$ M BCECF AM labeled monocyte counting and MTT labeled monocyte OD490nm absorbance value. Ox-LDL induced ICAM- 1 and VCAM-1 expression in the HUVECs after $12 \mathrm{~h}$ treatment. Tbx20 overexpression abolished ox-LDL-induced ICAM-1 and VCAM-1 expression, demonstrated with real time RTPCR and Western blot (Fig. 4I and 4J).

\section{Tbx20 ablation exaggerated ox-LDL-induced adhesion molecule expression}

Figure 5A-5C illustrates that two Tbx20 siRNAs (siRNA1 and siRNA2), but not the scramble siRNA (as a negative control), substantially reduced basal Tbx20 mRNA and protein abundance. The knock-down of Tbx20 in the HUVECs showed higher adhesion molecule expression compared with control and scramble groups(Fig. 5C), assayed by Western blot, suggesting a reduced tolerance to ox-LDL stimulation in the HUVECs with Tbx20 knockdown. For instance, after $12 \mathrm{~h}$ of ox-LDL treatment, the expression of VCAM-1 and ICAM-1 was significantly increased in the HUVECs with Tbx20 knock-down. Tbx20 knock-down also increased ROS production in the HUVECs assayed by DHE staining (Fig. 5D-5E). 


\section{Cellular Physiology Cell Physiol Biochem 2013;32:1137-1150 \\ \begin{tabular}{l|l|l} 
DOI: 10.1159/000354514 & O 2013 S. Karger AG, Basel
\end{tabular}

A.

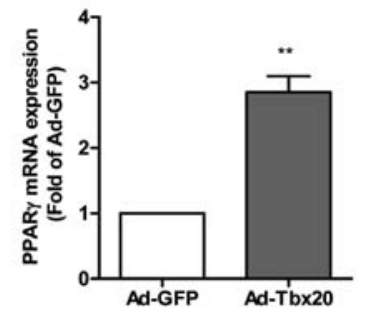

B.

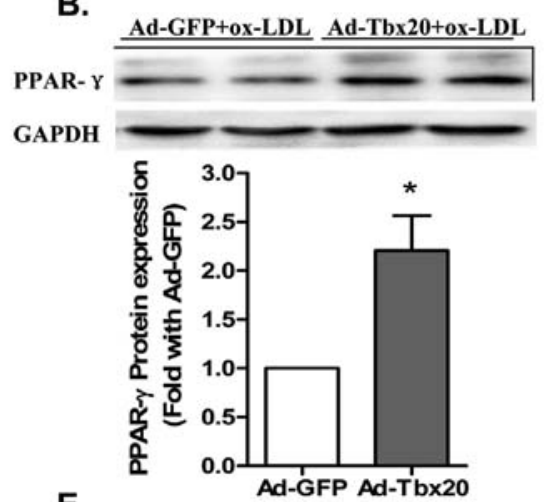

E.

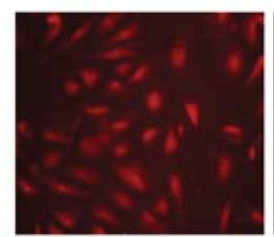

Ad-GFP

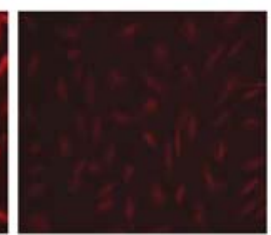

Ad-Tbx20

G.

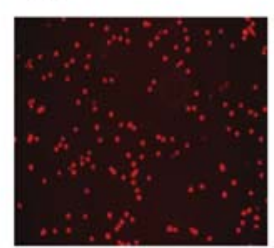

Ad-GFP

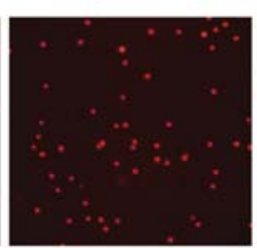

Ad-Tbx20
I.

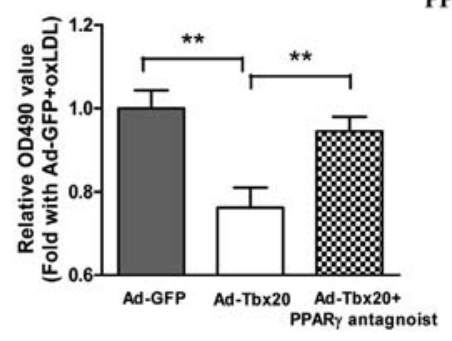

C.

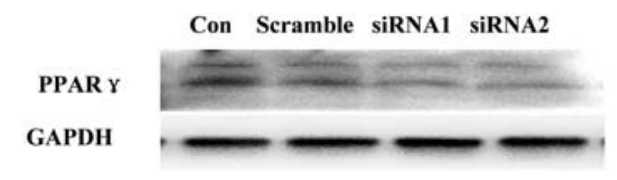

D.
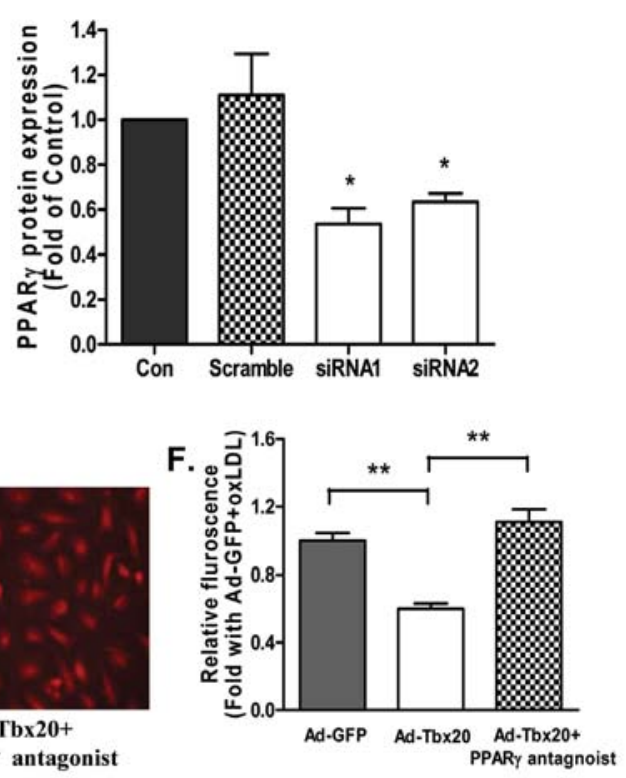

H.

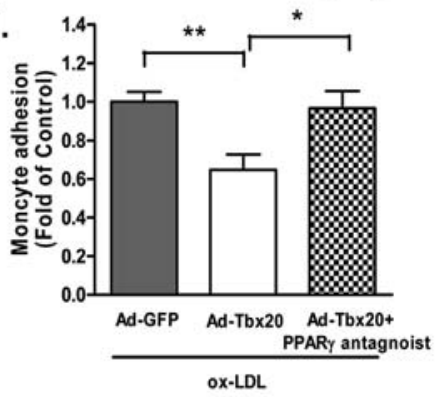

J.

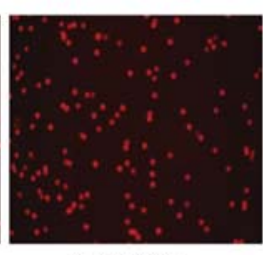

Ad-Tbx20+ PPAR $Y$ antagonist

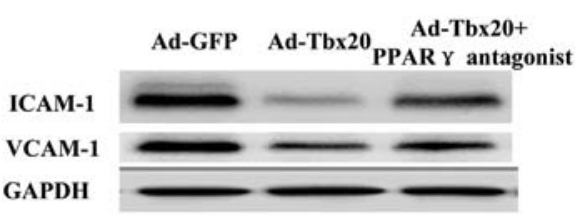

Fig. 6. Tbx20 attenuates ox-LDL-induced HUVEC injury by upreguation of PPAR- $\gamma$. (A-B): The levels of PPAR- $\gamma$ mRNA $(A)$ and protein $(B)$ assayed by real time PCR and Western blot in Ad-GFP and Ad-Tbx20-transduced HUVECs $(\mathrm{n}=3)$. $C$ - $D$ : PPAR- $\gamma$ protein expression and average data assayed Western blot in Tbx20 siRNAtransduced HUVECs (n=3). E-F: PPAR- $\gamma$ specific antagonist T0070907 could reverse the Tbx20's inhibition of ROS production after ox-LDL treatment assayed by DHE staining $(E)$ and the average data of fluorescence intensity $(F)(\mathrm{n}=3)$. $G$-H: Monocyte and HUVEC adhesion assay $(G)$ and the average data of cell counting $(H)$. (I): The relative OD490 value of monocyte and HUVEC adhesion assay by MTT labeled U937 cells. (J): Western blot analysis of ICAM-1 and VCAM-1 abundance in Ad-GFP, Ad-Tbx20, Ad-Tbx20+T0070907 treated HUVECs ( $n=3)$. 


\section{Cellular Physiology and Biochemistry}

Cell Physiol Biochem 2013;32:1137-1150

\begin{tabular}{l|l}
\hline DOI: $10.1159 / 000354514$ & (c) 2013 S. Karger AG, Basel
\end{tabular}

www.karger.com/cpb

Shen/Zhu/Patel et al.: T-Box20 Protects Vascular Endothelial Cells

Tbx20 regulated PPAR- $\gamma$ expression and protected the endothelial cells from ox-LDLinduced injury

Previous bioinformatics study showed several T-box binding sites in the PPAR- $\gamma$ promoter region. We found that the levels of PPAR- $\gamma$ mRNA and protein were significantly increased in the Tbx20 overexpressed HUVECs compared to the Ad-GFP control group (Fig. $6 \mathrm{~A}$ and 6B). On the other hand, transduceion of Tbx20 siRNA in the HUVECs decreased PPAR- $\gamma$ expression (Fig. 6C and 6D). PPAR- $\gamma$ specific antagonist T0070907 reversed the attenuation of ROS production effect in the Tbx20 overexpressed HUVECs, as assayed by DHE staining (Fig. 6E-6F). The PPAR- $\gamma$ antagonist also reversed Tbx20-induced attenuation of monocyte adhesion to HUVECs after ox-LDL treatment, as assayed by BCECF AM or MTT labeled monocyte and HUVEC adhesion assay (Fig. 6G-6I). Moreover, the PPAR- $\gamma$ specific antagonist T0070907 restored adhesion molecule expression in the Tbx20-overexpressed HUVECs treated by ox-LDL, as assayed by Western blot (Fig. 6J).

\section{Discussion}

In the present study, we provided multiple lines of evidence to define Tbx20 as a critical component involved in protection mechanism of the endothelial cells against oxidative stress.

Tbx20 is critical to endothelial cell function and is suppressed by the initiation of atherosclerosis

It has been previously demonstrated that ox-LDL induced ROS generation and was involved in cellular injury through various pathways [2, 4, 30-32]. We used the high-fat diet-induced C57BL/6 mouse artery injury model and ox-LDL treated HUVECs to model this process. The consistent findings across both of these models were decreased Tbx20 expression, increased adhesion molecule expression and high apoptotic cell rate.

Potential pathological implications of Tbx20 in endothelial cell viability by antiinflammation and oxidative stress in the pathogenesis of atherosclerosis

We found that Tb20 overexpression reversed ox-LDL-induced HUVEC injury phenotype. Tbx20 overexpression resulted in a significant reduction in markers of oxidative stress and superoxide dismutase (SOD) activity. Also, Tbx20 overexpression led to a decrease in apoptosis of the ox-LDL-treated HUVECs. This is significant because atherosclerosis has been associated with progressive endothelial cell loss [33,34]. We provide a potential mechanism by which Tbx20 overexpression blocked oxidative injury, namely the inhibition of the Bax and caspase 3 pathways. Conversely, Tbx20 knock-down increased ROS generation in the HUVECs. In our experiments, overexpression of Tbx20 could block oxidative stress in the endothelia cells and then inhibit the activation of caspase 3 and Bax. The inhibition of caspase 3 and Bax is followed by decreased oxidative stress. Caspase- 3 is activated in the apoptotic cells by both extrinsic (death ligand) and intrinsic (mitochondrial) pathways. As an executioner caspase, the caspase- 3 zymogen has virtually no activity until it is cleaved by an initiator caspase after apoptotic signaling events have occurred. The full length caspase- 3 is formed a $32 \mathrm{kDa}$ zymogen, which does not induce apoptosis. However, the full length caspase- 3 is cleaved into two subunits, $17 \mathrm{kDa}$ large subunits and $12 \mathrm{kDa}$ small subunits, by the apoptotic stimuli, indicating the activation of caspase-3. Normally, the apoptotic cells have less full length caspase- 3 and more cleaved caspase- 3 than the healthy cells. As shown in figure 4E, Tbx20 overexpression in the HUVECs led to increased levels of full length caspase- 3 and decreased levels of cleaved caspase-3, suggesting that the apoptotic cell rate was decreased. Therefore, the data support our conclusion that Tbx20 could protect the HUVECs from apoptosis. 


\section{Cellular Physiology and Biochemistry}

Cell Physiol Biochem 2013;32:1137-1150

\begin{tabular}{l|l}
\hline DOI: $10.1159 / 000354514$ & (C) 2013 S. Karger AG, Basel
\end{tabular}

www.karger.com/cpb

Shen/Zhu/Patel et al.: T-Box20 Protects Vascular Endothelial Cells

Potential pathological implications of Tbx20 attenuating adhesion molecule expression in the pathogenesis of atherosclerosis

In high fat diet-induced mouse artery injury models, ICAM-1 and VCAM-1 are thought to play a key role in the early stage of the inflammatory response, through the facilitation of leukocyte adhesion and transmigration in the vascular endothelium. Therefore, it is significant that we observed that Tbx20 overexpression in the HUVECs caused an inhibition of VCAM-1 and ICAM-1 expression, which indeed correlated to significantly reduced monocyte adhesion in our HUVEC model. Conversely, Tbx20 knock-down significantly increased VCAM1 and ICAM-1 expression. Collectively, these data suggest that the effect of Tbx20 on vascular injury is mediated, at least in part, by modulation of inflammatory cell adhesion.

Tbx20 plays a role in endothelial cell protection by upregation of PPAR- $\gamma$

Previous bioinfomatic and ChIP-seq study identified PPAR- $\gamma$ (peroxisome proliferatoractivated receptor gamma) as a downstream target of Tbx20 [20]. Since PPAR- $\gamma$ activation decreased inflammatory response expression of adhesion molecules in the activated human endothelial cells $[22,23,26]$, we sought to clarify the relationship between Tbx20 and PPAR- $\gamma$.

We found that overexpression of Tbx20 caused an upregulation of PPAR- $\gamma$ expression, whereas as knock-down of Tbx20 had the opposite effect on PPAR- $\gamma$ expression. Moreover, we found that the PPAR- $\gamma$ specific antagonist T0070907 reversed Tbx20's inhibition of adhesion molecule expression in ox-LDL treated HUVECs. Collectively, this evidence suggests PPAR- $\gamma$ as the transcriptional product that is responsible for Tbx20's endothelial cell-protection effect during ox-LDL injury. However, there is much work to be done to completely outline the pathways linking these whole cell effects, PPAR- $\gamma$ regulation, and Tbx20. We are currently investigating these links in more detail, especially in regards to PPAR- $\gamma$ induction in vivo.

The translation of our present bench discoveries into clinical medicine will require several important issues to be addressed. First, although our study clearly indicates that Tbx20 is necessary for endothelial cell protection, it remains to be determined how Tbx20 regulates PPAR- $\gamma$ expression. Second, others have recently identified that Tbx20 plays an important role in regulating the calcium and potassium channel and cell homeostasis in the heart, which may account for its protective effect. It is unclear whether this heart protection and hemodynamic effect is related to endothelial cell function or not. These issues will require further study to better define the role of Tbx20 in the protection of endothelium from injury.

\section{Conclusions}

In summary, we demonstrated for the first time that Tbx20 is markedly reduced during artery and endothelial cell injury. We also suggested that Tbx20 overexpression is sufficient to protect the endothelial cell from injury through an anti-inflammatory and anti-oxidative effect. Moreover, we identified the increase in PPAR- $\gamma$, a molecule that has been shown to be involved with anti-inflammatory effects in the endothelial cells, as a potential mechanism for this effect of Tbx20. We concluded that the inhibition of the transcription factor Tbx20 is crucial for the initiation of atherosclerosis, because of the Tbx20 role in the gene regulation in response to atherogenic stimulation. The present findings might reveal new drug targets and therapeutic strategies for these scourges to humanity.

\section{Conflict of Interest}

None declared. 


\section{Cellular Physiology and Biochemistry}

Cell Physiol Biochem 2013;32:1137-1150

\begin{tabular}{l|l}
\hline DOI: $10.1159 / 000354514$ & (C) 2013 S. Karger AG, Basel
\end{tabular}

www.karger.com/cpb

Shen/Zhu/Patel et al.: T-Box20 Protects Vascular Endothelial Cells

\section{Acknowledgements}

This work is supported by grants from National Basic Research Program of China (2012CB517502), National Natural Science Foundation of China (81200221, 81070634, 30900627, 81270854) and Scientific Research Foundation for Returned Chinese Scholars of the Ministry of Human Resource and Social Security of the People's Republic of China. Contributors do not warrant authorship.

\section{References}

1 Mannarino E, Pirro M: Molecular biology of atherosclerosis. Clin Cases Miner Bone Metab 2008;5:57-62.

$>2$ Mitra S, Deshmukh A, Sachdeva R, Lu J, Mehta JL: Oxidized low-density lipoprotein and atherosclerosis implications in antioxidant therapy. Am J Med Sci 2011;342:135-142.

- 3 Chen CH, Jiang W, Via DP, Luo S, Li TR, Lee YT, Henry PD: Oxidized low-density lipoproteins inhibit endothelial cell proliferation by suppressing basic fibroblast growth factor expression. Circulation 2000;101:171-177.

4 Inoue M, Itoh H, Tanaka T, Chun TH, Doi K, Fukunaga Y, Sawada N, Yamshita J, Masatsugu K, Saito T, Sakaguchi S, Sone M, Yamahara Ki, Yurugi T, Nakao K: Oxidized LDL regulates vascular endothelial growth factor expression in human macrophages and endothelial cells through activation of peroxisome proliferator-activated receptor-gamma. Arterioscler Thromb Vasc Biol 2001;21:560-566.

5 Kuzuya M, Ramos MA, Kanda S, Koike T, Asai T, Maeda K Shitara K, Shibuya M, Iguchi A: VEGF protects against oxidized LDL toxicity to endothelial cells by an intracellular glutathione-dependent mechanism through the KDR receptor. Arterioscler Thromb Vasc Biol 2001;21:765-770.

6 Jovinge S, Ares MP, Kallin B, Nilsson J: Human monocytes/macrophages release TNF-alpha in response to Ox-LDL. Arterioscler Thromb Vasc Biol 1996;16:1573-1579.

7 Erl W, Weber PC, Weber C: Monocytic cell adhesion to endothelial cells stimulated by oxidized low density lipoprotein is mediated by distinct endothelial ligands. Atherosclerosis 1998;136:297-303.

8 Davignon J, Ganz P: Role of endothelial dysfunction in atherosclerosis. Circulation 2004;109:III27-III32.

-9 Thorin-Trescases N, Voghel G, Gendron ME, Krummen S, Farhat N, Drouin A Perrault LP, Thorin E: Pathological aging of the vascular endothelium: are endothelial progenitor cells the sentinels of the cardiovascular system? Can J Cardiol 2005;21:1019-1024.

10 Chen YH, Lin SJ, Chen YL, Liu PL, Chen JW: Anti-inflammatory effects of different drugs/agents with antioxidant property on endothelial expression of adhesion molecules. Cardiovasc Hematol Disord Drug Targets 2006;6:279-304.

$\checkmark 11$ Zhang J, Alcaide P, Liu L, Sun J, He A, Luscinskas FW, Shi GP: Regulation of endothelial cell adhesion molecule expression by mast cells, macrophages, and neutrophils. PLoS One 2011;6:e14525.

12 Takahashi M, Ikeda U, Masuyama J, Kitagawa S, Kasahara T, Shimpo M, Kano S, Shimada K: Monocyteendothelial cell interaction induces expression of adhesion molecules on human umbilical cord endothelial cells. Cardiovasc Res 1996;32:422-429.

13 Zhu YP, Shen T, Lin YJ, Chen BD, Ruan Y, Cao Y, Qiao Y, Man Y, Wang S, Li J: Astragalus polysaccharides suppress ICAM-1 and VCAM-1 expression in TNF- $\alpha$-treated human vascular endothelial cells by blocking NF- $\kappa$ B activation. Acta Pharmacol Sin 2013;34:1036-1042.

14 Kiefer JC: The Tbx-files: the truth is out there. Dev Dyn 2004;231:232-236.

15 Iio A, Koide M, Hidaka K, Morisaki T: Expression pattern of novel chick T-box gene, Tbx20. Dev Genes Evol 2001;211:559-562.

16 Cai CL, Zhou W, Yang L, Bu L, Qyang Y, Zhang X, Li X, Rosenfeld MG, Chen J, Evans S: T-box genes coordinate regional rates of proliferation and regional specification during cardiogenesis. Development 2005;132:2475-2487.

-17 Kraus F, Haenig B, Kispert A: Cloning and expression analysis of the mouse T-box gene tbx20. Mech Dev 2001;100:87-91. 


\section{Cellular Physiology and Biochemistry}

Cell Physiol Biochem 2013;32:1137-1150

Shen/Zhu/Patel et al.: T-Box20 Protects Vascular Endothelial Cells

18 Kirk EP, Sunde M, Costa MW, Rankin SA, Wolstein O, Castro ML, Butler TL, Hyun C, Guo G, Otway R, Mackay JP, Waddell LB, Cole AD, Hayward C, Keogh A, Macdonald P, Griffiths L, Fatkin D, Sholler GF, Zorn AM, Feneley MP, Winlaw DS, Harvey RP: Mutations in cardiac T-box factor gene TBX20 are associated with diverse cardiac pathologies, including defects of septation and valvulogenesis and cardiomyopathy. Am J Hum Genet 2007;81:280-291.

19 Shen T, Aneas I, Sakabe N, Dirschinger RJ, Wang G, Smemo S, Westlund JM, Cheng H, Dalton N, Gu Y, Boogerd CJ, Cai CL, Peterson K, Chen J, Nobrega MA, Evans SM: Tbx20 regulates a genetic program essential to adult mouse cardiomyocyte function. J Clin Invest 2011;121:4640-4654.

20 Sakabe NJ, Aneas I, Shen T, Shokri L, Park SY, Bulyk ML, Evans SM, Nobrega MA: Dual transcriptional activator and repressor roles of TBX20 regulate adult cardiac structure and function. Hum Mol Genet 2012;21:2194-2204.

-21 Calabro P, Samudio I, Safe SH, Willerson JT, Yeh ET: Inhibition of tumor-necrosis-factor-alpha induced endothelial cell activation by a new class of PPAR- $\gamma$ agonists. An in vitro study showing receptorindependent effects. J Vasc Res 2005;42:509-516.

22 Hamblin M, Chang L, Fan Y, Zhang J, Chen YE: PPARs and the cardiovascular system. Antioxid Redox Signal 2009;11:1415-1452.

23 Cantini G, Lombardi A, Borgogni E, Francalanci M, Ceni E, Degl'Innocenti S Gelmini S, Poli G, Galli A, Serio M, Forti G, Luconi M: Peroxisome-proliferator-activated receptor gamma (PPARgamma) is required for modulating endothelial inflammatory response through a nongenomic mechanism. Eur J Cell Biol 2010;89:645-653.

24 Orasanu G, Ziouzenkova O, Devchand PR, Nehra V, Hamdy O, Horton ES, Plutzky J: The peroxisome proliferator-activated receptor-gamma agonist pioglitazone represses inflammation in a peroxisome proliferator-activated receptor-alpha-dependent manner in vitro and in vivo in mice. J Am Coll Cardiol 2008;52:869-881.

25 Zieleniak A, Wojcik M, Wozniak LA: Structure and physiological functions of the human peroxisome proliferator-activated receptor gamma. Arch Immunol Ther Exp (Warsz ) 2008;56:331-345.

-26 Derosa G, Maffioli P: Peroxisome proliferator-activated receptor-gamma (PPAR-gamma) agonists on glycemic control, lipid profile and cardiovascular risk. Curr Mol Pharmacol 2012;5:272-281.

-27 Jaffe EA, Nachman RL, Becker CG, Minick CR: Culture of human endothelial cells derived from umbilical veins. Identification by morphologic and immunologic criteria. J Clin Invest 1973;52:2745-2756.

28 Chen B, Zhao J, Zhang S, Wu W, Qi R: Aspirin inhibits the production of reactive oxygen species by downregulating Nox4 and inducible nitric oxide synthase in human endothelial cells exposed to oxidized low-density lipoprotein. J Cardiovasc Pharmacol 2012;59:405-412.

29 Shen T, Zheng M, Cao C, Chen C, Tang J, Zhang W, Cheng H, Chen KH, Xiao RP: Mitofusin-2 is a major determinant of oxidative stress-mediated heart muscle cell apoptosis. J Biol Chem 2007;282:23354-23361.

-30 Natarajan R, Nadler JL: Lipid inflammatory mediators in diabetic vascular disease. Arterioscler Thromb Vasc Biol 2004;24:1542-1548.

-31 Lu Y, Qin W, Shen T, Dou L, Man Y, Wang S, Xiao C, Li J: The antioxidant N-acetylcysteine promotes atherosclerotic plaque stabilization through suppression of RAGE, MMPs and NF-kappaB in ApoE-deficient mice. J Atheroscler Thromb 2011;18:998-1008.

-32 Hsieh CC, Yen MH, Yen CH, Lau YT: Oxidized low density lipoprotein induces apoptosis via generation of reactive oxygen species in vascular smooth muscle cells. Cardiovasc Res 2001;49:135-145.

33 Yung LM, Leung FP, Yao X, Chen ZY, Huang Y: Reactive oxygen species in vascular wall. Cardiovasc Hematol Disord Drug Targets 2006;6:1-19.

-34 Ray R, Shah AM: NADPH oxidase and endothelial cell function. Clin Sci (Lond) 2005;109:217-226. 